\title{
Discharge Coefficient for Sharp-Crested Side Weir in Supercritical Flow
}

\author{
K.P.P. Pathirana, M.M. Munas and A.L.A. Jaleel
}

\begin{abstract}
The characteristics of flow over side weirs are completely different from that of weirs normal to the approach channel. An accurate computation of discharge over a side weir mainly depends on the proper estimation of the discharge coefficient. The discharge coefficient of a rectangular, sharp-crested side weir under supercritical flow has been investigated using experimental data. The assumption of constancy of specific energy across a side weir is valid for supercritical flows generated in this study. The experimental data was analysed using multiple regression analysis with different non-dimensional parameters relevant to the problem. Moreover, a numerical solution to the equation of spatially varied flow was also proposed. The coefficient of discharge has been related to the upstream Froude number, and the ratios of the upstream water depth to the weir height and the weir length to the main channel width.
\end{abstract}

Keywords: Side weir, Supercritical flow, Discharge coefficient, Spatially varied flow

\section{1.' Introduction}

A side weir, also known as a lateral weir, is an over flow weir formed in the side of a channel with the purpose of allowing part of the liquid to spill over the side when the surface of the flow in the channel rises above the weir crest. Side weirs are extensively used in irrigation, land drainage, flood control and urban drainage works. Particularly in irrigation canal networks, these structures are often used as head regulators of distributaries and escapes.

The flow over a side weir varies gradually with decreasing discharge. A complete analytical solution of the equations governing the weir discharge is not possible as there are many parameters influencing the flow phenomenon. Due to the transverse variation of flow profile and velocity distribution, the hydraulic behaviour over a side weir is completely different from that over a weir normal to the approach channel. In addition, the flow in the approach channel along a side weir can be subcritical or supercritical depending on which, the flow characteristics vary at the side weir leading to different weir discharges.

Many studies have been carried out in the past to investigate the discharge over side weirs under subcritical flows (Subramanaya et al [15]; El Khashab et al [3]; Ranga Raju et al [13]; Hager [6]; Singh [14]; Swamee et al [16,17]; Borghei et al [2] and many others) and very few studies are reported on side weir flow with supercritical flow. The side weir with supercritical approach flows are also of much interest to civil engineers as such conditions are encountered in practice, particularly in relatively steep and smooth channels. Hager [5] presented an analysis of a supercritical flow in a prismatic side weir with a circular-shaped channel section. Hydraulic features along a prismatic side weir in a circular channel were investigated by Oliveto et al [10] using a theoretical analysis supported by a limited number of experimental data. Ghodsian [4] investigated the supercritical flow in a rectangular side weir using numerical analysis. In the present study, the supercritical flow over a rectangular, sharp-crested side weir is examined with experimental data, in an attempt to provide further details on the same phenomenon as another contribution to the studies on side weirs with a supercritical flow.

\section{Theoretical Aspects}

The conservation of energy principle is used for the analysis of spatially varied flow with decreasing discharge. Let $\mathrm{z}$ be the distance of the bottom of a channel section above a horizontal datum, the total energy at the channel section is;

Eng.(Dr.) K.P.P. Pathirnna. B.Sc. Eng. (Hons.)YPerndeniya), M.Eng., Ph.D., C.Eng., FIE(SL), MICE, Senlor Lecturer. Department of Civil Engineering, University of Peradeniyn.

M.M. Munas, B.Sr. Eng. (Hons), Department of Civil Engineering. University of Pemdeniyn.

A.L.A. Jaleel, B.St: Eng. (Hons), Department of Civil Engineering. University of Peradeniya. 
$H=z+y+\frac{\alpha Q^{2}}{2 g A^{2}}$

Differentiating this equation with respect to $x$ and substituting, $\frac{d H}{d x}=-S_{f}, \frac{d z}{d x}=-S_{0}$ and $\frac{d A}{d x}=B \frac{d y}{d x}$ gives;

$\frac{d y}{d x}=\frac{S_{0}-S_{f}-\left(\frac{\alpha Q}{g A^{2}}\right)\left(\frac{d Q}{d x}\right)}{1-\left(\frac{\alpha Q^{2} B}{g A^{3}}\right)}$

where, $y=$ depth flow in the main channel, $x=$ longitudinal direction, $\mathrm{S}_{f}=$ friction slope, $\mathrm{S}_{0}=$ longitudinal slope of the channel, $A=$ cross sectional area, $B=$ channel width, $\alpha=$ kinetic energy correction coefficient.
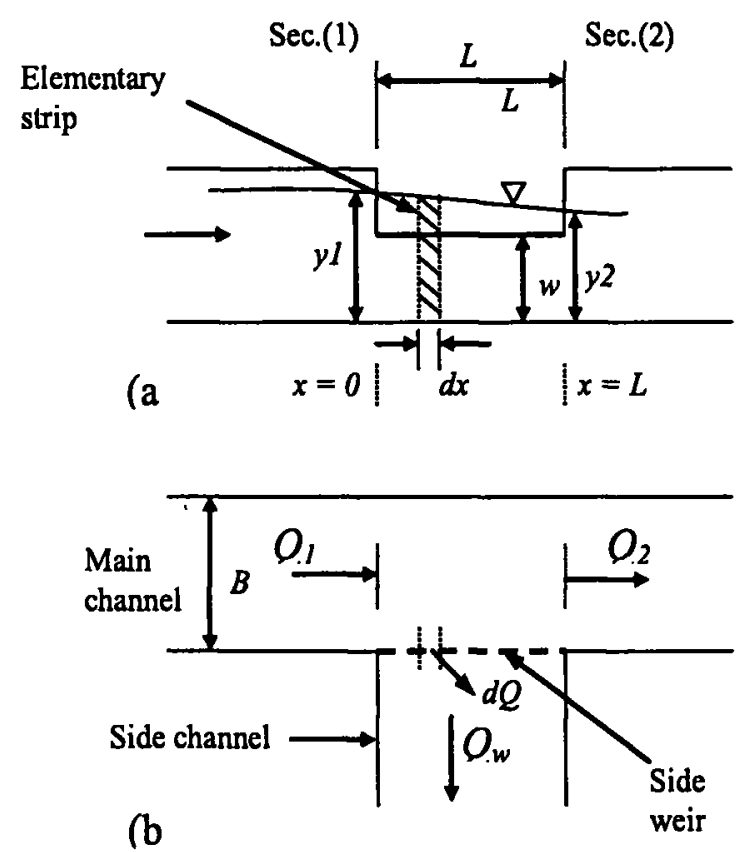

Figure 1- Flow over a side weir (a) longitudinal section and (b) plan view.

The computation of discharge over a side weir becomes more complicated as the velocity through the side weir is not at a right angle to the weir as in the case of a weir placed normal to the approach channel. However, assuming that specific energy is constant across the weir, the discharge $d Q$ through an elementary strip of length $d x$ along the weir (see Figure 1 ) is computed using a normal weir formula as follows: $q=-\frac{d Q}{d x}=-\frac{2}{3} C_{m} \sqrt{2 g}(y-w)^{3 / 2}$

where $w=$ height of the side weir, $q=$ discharge per unit length of side weir and $C_{m}=$ elementary discharge coefficient of the strip which is also known as De-Marchi coefficient of discharge (Chow [1]).

Using Manning's equation, the energy slope, $S_{f}$ can be written as;

$S_{f}=\frac{n^{2} Q^{2}}{A^{2} R^{4 / 3}}$

where $n=$ Manning's coefficient and $R=$ hydraulic radius. Substituting Eqs. (3) and (4) in Eq. (2), the following relationship is obtained.

$\frac{d y}{d x}=\frac{S_{0}-\frac{n^{2} Q^{2}}{A^{2} R^{4 / 3}}+\frac{2 \sqrt{2 g} C_{m}}{3}\left(\frac{\alpha Q}{g A^{2}}\right)(y-w)^{3 / 2}}{1-\left(\frac{\alpha Q^{2} B}{g A^{3}}\right)}$

If the elementary discharge coefficient is known, this equation can be solved using a fourth-order Runge-Kutta method considering this as an initial value problem. The following initial condition can be used to start the computations;

At $x=0, y=y_{1}$ and $Q=Q_{1}$

where $y_{1}$ and $Q_{1}$ are upstream flow depth and discharge, respectively. The water depth and discharge at a distance $\mathrm{dx}$ along the weir will be given as a solution to the above equation. The repeated computations ultimately yield the water depth $\left(y_{2}\right)$ and discharge $\left(Q_{2}\right)$ at the downstream of the side weir and hence, the computed discharge over the side weir $\left(Q_{w}\right)$ is given by;

$Q_{\mathrm{w}}=Q_{1}-Q_{2}$

The discharge coefficient, $C_{m}$ depends on many parameters related to geometrical configuration of the main channel and the side weir arrangement and characteristics of flow in the main channel. By using dimensional analysis, $C_{m}$ can be expressed in non-dimensional quantities that are more significant as; 
$C_{m}=f\left(F r_{1}, \frac{w}{y_{1}}, \frac{L}{B}\right)$

where, $F r_{1}=$ Froude number in the main channel $\left(-V_{1} / \sqrt{8 y_{1}}\right), V_{1}=$ mean velocity of flow at section (1) and $L=$ length of side weir. The influence of channel slope on $C_{m}$ is reported to be negligible (Borghei [2]).

\section{Experimental Details}

The experiments were carried out in a $13.5 \mathrm{~m}$ long, $0.3 \mathrm{~m}$ wide, $0.3 \mathrm{~m}$ deep rectangular, recirculating flume in the Hydraulics Laboratory of the Faculty of Engineering, University of Peradeniya. The channel width was reduced to $0.2 \mathrm{~m}$ in the last $6 \mathrm{~m}$ stretch of the channel in order to establish a supercritical flow at the side weir section. A schematic diagram of the experimental set-up is shown in Figure 2. The sharp-crested weir was built of aluminium plate, the top edge being suitably beveled to get a sharp crest. The side weir was framed to a wall of the main channel at a height of $0.06 \mathrm{~m}$ leading to a side channel of rectangular cross section and the weir height was kept constant during all experimental runs. Water was supplied to the main channel from an overhead tank at constant head and the flow was controlled by a gate valve.

Once the length of the side weir was adjusted to a pre-determined value, a certain discharge was allowed into the main channel. Flow depths at upstream, mid point and downstream locations of the side weir were measured along the center line of the main channel using a point gauge with an accuracy of $0.1 \mathrm{~mm}$. The flow in the main channel passing the weir section was measured using a calibrated V-notch fitted to the downstream tank. The discharge passing over the side weir was also accurately estimated by measuring the time taken to collect a known weight of water. The experiments were repeated for six different weir lengths and for each of the weir lengths; tests were carried out for five different discharges. The slope of the main channel was kept horizontal for all experimental runs. The flow over the side weir can be considered as unrestricted for all test cases, as the width of the side channel is relatively wider than the weir length so that the jet of water entering the side channel is not constrained by the walls of the side channel. The range of hydraulic parameters used in the tests is given in Table 1. The Manning's coefficient of the main channel was estimated using accurate discharge measurements in the channel prior to the commencement of actual test runs.

Table 1 - Summary of experimental data

\begin{tabular}{|l|l|}
\hline Parameter & Range \\
\hline Weir length, $L(\mathrm{~m})$ & $0.10-0.20$ \\
Main channel discharge, & \\
$Q_{1}\left(\mathrm{~m}^{3} / \mathrm{s}\right)$ & $0.0156-0.0242$ \\
Side channel discharge, & \\
$Q_{\mathrm{w}}\left(\mathrm{m}^{3} / \mathrm{s}\right)$ & $0.00035-0.00146$ \\
Upstream depth of flow, & \\
$y_{1}(\mathrm{~m})$ & $0.0795-0.1040$ \\
Upstream Froude & \\
number, $F r_{1}$ & $1.1-1.3$ \\
Manning's coefficient, $n$ & 0.011 \\
Energy correction & \\
factor, $(\alpha)$ & 1.0 \\
\hline
\end{tabular}

\section{From overhead}

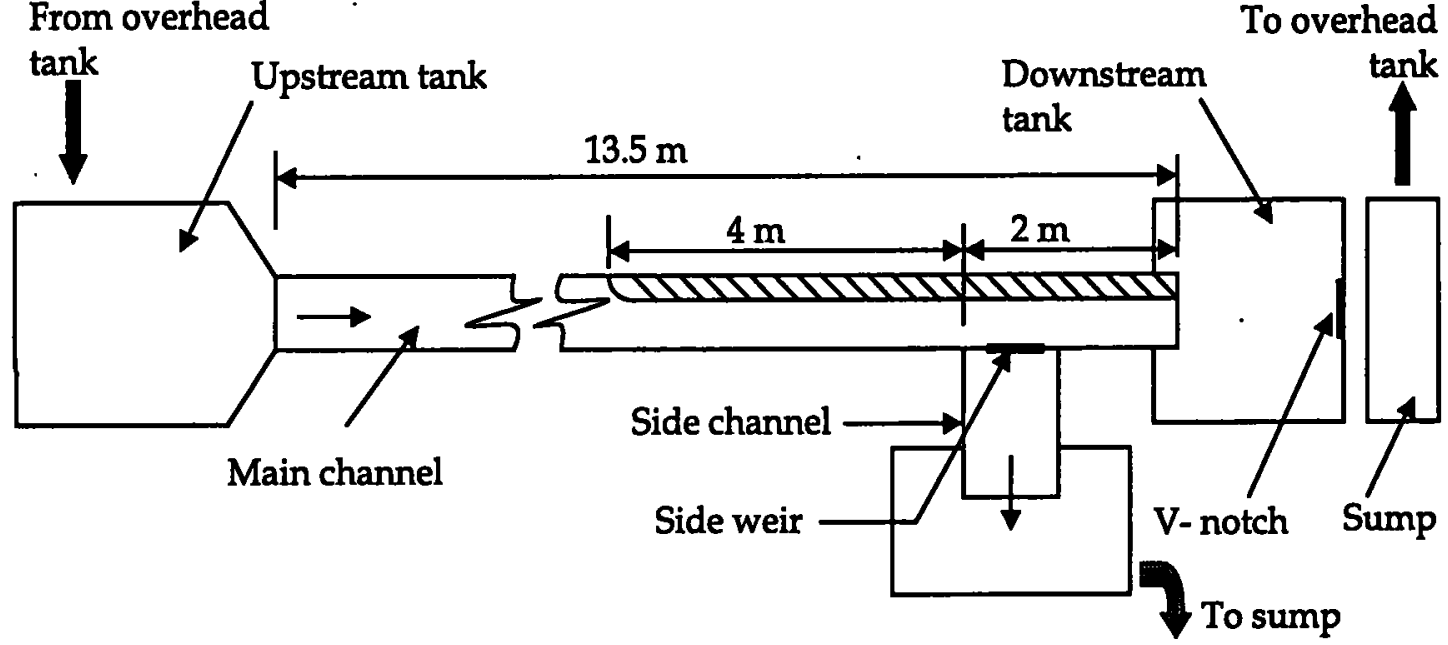

Figure 2- Plan view of the experimental set-up (- not to scale -). 


\section{Data Analysis}

The constant specific energy across the weir has been one of the assumptions used to derive the governing equation for discharge over a side weir and hence, it is important to check the validity of this assumption before proceeding to the data analysis in detail. Figure 3 illustrates a comparison of specific energy at the upstream and downstream ends of the side weir. It can be seen that two specific energies are approximately close to each other though there is a slight energy loss for certain test cases which were related to higher discharges and narrow weir lengths. The average energy reduction is found to be about 3\%. EI-Khashab et al [3] and Borghei et al [2] have also obtained somewhat similar results for their experiments carried out with subcritical flows and the average energy differences obtained were $5 \%$ and $3.7 \%$, respectively. Therefore, it can be concluded that the assumption of constant specific energy is valid even for supercritical flows at least for the range of Froude numbers used in this study.

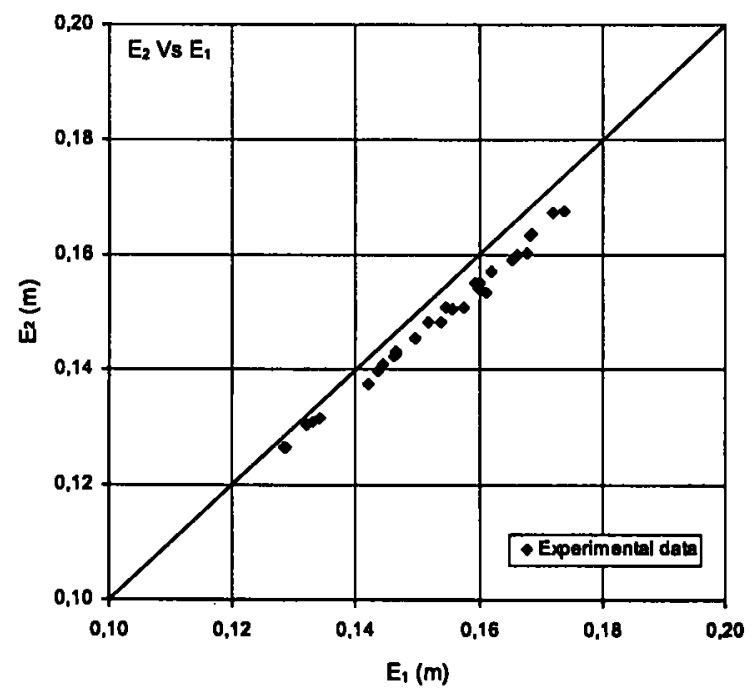

Figure 3 - Comparison of specific energy at upstream and downstreain ends of side tueir.

Two independent approaches were used to analyse the experimental data. At first, the data was analysed using regression analysis to establish correlations between the discharge coefficient and different non-dimensional quantities outlined in Eq. (8) and the details are presented in Sec. (4.1). Secondly, a numerical solution to the governing equation of spatially varied flow (Eq. 5) is proposed. Details of this method are given in Sec. (4.2).

\subsection{Regression Analysis}

The discharge coefficients for all test cases were computed using Eq. (3) with the measured weir discharges and the corresponding flow depths at mid point locations of the side weir. The nondimensional parameters defined in Eq.(8) were plotted against the discharge coefficient in order to study the influence of different variables of the problem on the discharge coefficient. The variation of $C_{m}$ with $F r_{1}, u / y_{1}$ and $(L / B)^{2}$ are shown in Figures 4 to 6, respectively. It appears that the correlations between $C_{m}$ and these nondimensional parameters are poor.

Although data points are somewhat scattered in Figure 4 , the mean value of the discharge coefficient appears to increase with upstream Froude numbers and then reaches a constant value when $F r_{1}$ is greater that about 1.18. The number of test runs conducted in this study is inadequate to reliably confirm the accuracy of numerical values indicated here. However, a similar behaviour was also noted from the functional relationship proposed by Ghodsian [4] for the discharge coefficient for a side weir with supercritical flow. According to his relationship, the effect of $F r_{1}$ on $C_{m}$ gradually reduces with increasing $F r_{1}$. On the contrary, the behaviour with subcritical flow is reported to be completely different as the coefficient $C_{m}$ gradually decreases with $F r_{1}$ (Borghei et al [2] and Hager [5]). Swamee et al [17] has given an excellent comparison of different relationships reported in the literature to estimate discharge coefficients using $F r_{1}$ for subcritical flows.

The following relationship was obtained for $C_{m}$ versus $F r_{1}$ as a line of best fit to the data shown in Figure 4.

$$
C_{m}=-7.88 F r_{1}^{2}+18.76 F r_{1}-10.77
$$

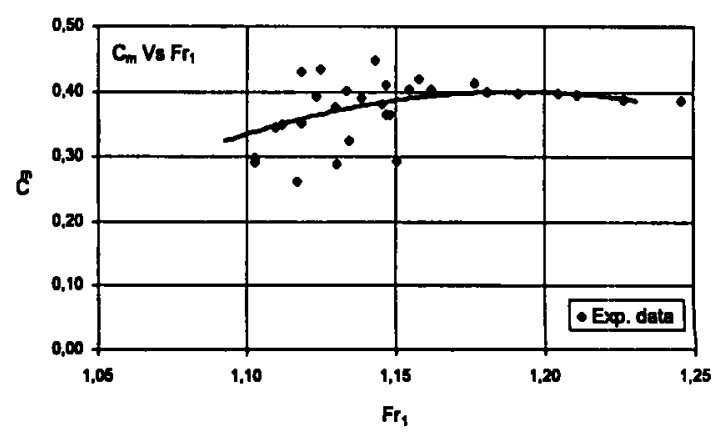

Figure 4 - Variation of $C_{m}$ with $F r_{r}$. 


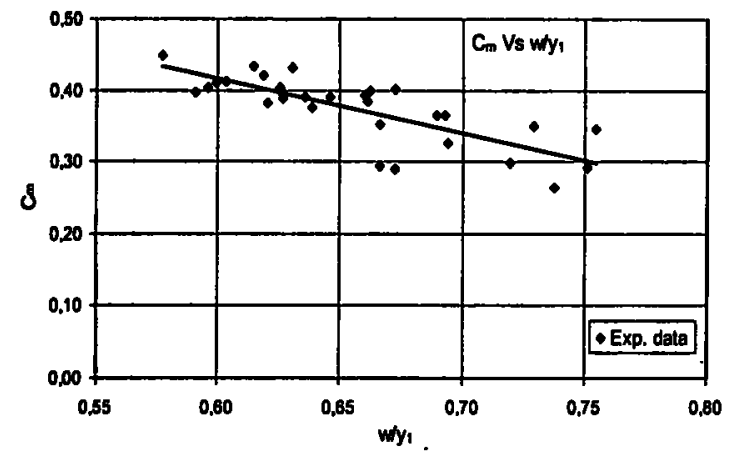

Figure 5 - Variation of $C_{m}$ with $w / y_{r}$

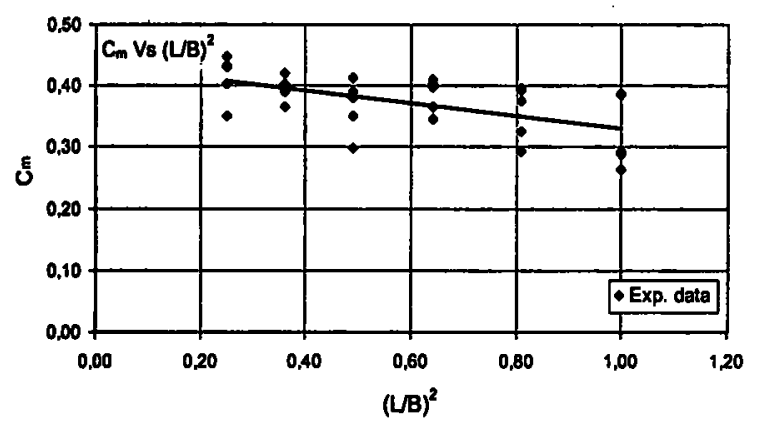

Figure 6 - Variation of $C_{m}$ with $(L / B)^{2}$.

The data plotted in Figure 5 shows that the coefficient $C_{m}$ gradually decreases with $\left(w / y_{1}\right)$ and a similar behaviour was noted for the tests conducted with subcritical flows (Borghei et al [2]). The least square method gives the following quadratic equation for the relationship between $C_{m}$ and $\left(w / y_{1}\right)$.

$C_{m}=0.58\left(\frac{w}{y_{1}}\right)^{2}-1.54\left(\frac{w}{y_{1}}\right)+1.13$

A very poor correlation is observed between $C_{m}$ and $(L / B)^{2}$; however, the average value of $C_{m}$ gradually decreases with $(L / B)^{2}$. The following linear relationship was obtained as a best line to fit the data shown in Figure 6.

$C_{m}=-0.104\left(\frac{L}{B}\right)^{2}+0.435$

Figure 7 shows a comparison between measured and computed discharges using discharge coefficients estimated by Eqs.(9) to (11). The scattering of data points in this graph seems to indicate that the weir discharge cannot be accurately predicted using the discharge coefficients that are based on individual nondimensional parameters.

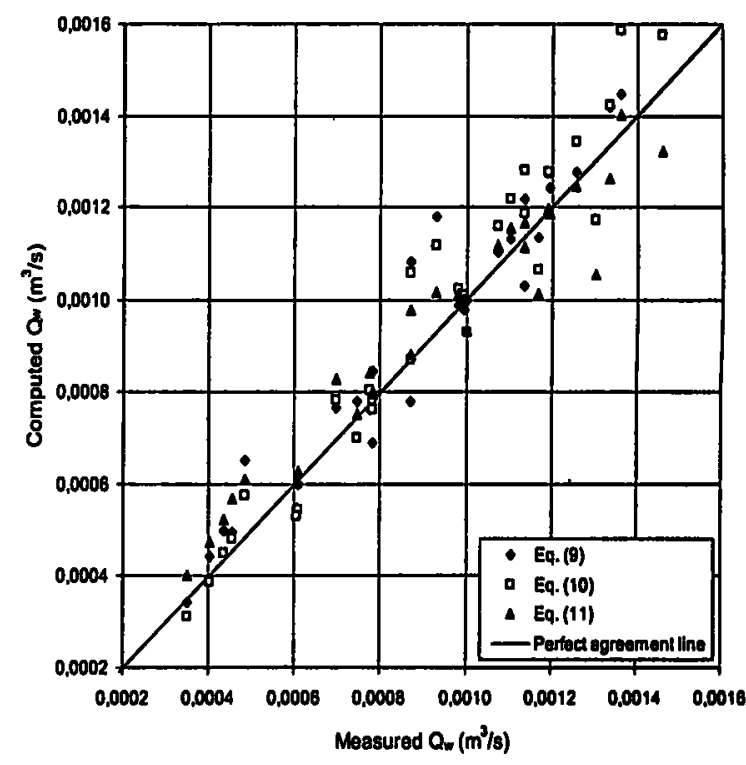

Figure 7 - Comparison between measured and computed discharges.

Table 2 indicates the average percentage errors between measured and computed discharges using different equations. The relationships given for $C_{m}$ which are based on one parameter of each $F r_{1}, w / y_{1}$ and $(L / B)^{2}$ has given the average percentage errors of $8.0,8.3$ and 7.8 , respectively.

In order to incorporate the influence of all nondimensional parameters on the discharge coefficient, multiple regression analysis was used on the data set and the following linear equation was obtained.

$C_{m}=0.137+0.499 F r_{1}-0.748\left(\frac{w}{y_{1}}\right)-0.104\left(\frac{L}{B}\right)^{2}$

The inclusion of all non-dimensional parameters in the same relationship to estimate $C_{m}$ has produced much improved results for the weir discharge as shown in Figure 8. The computed weir discharges are slightly higher than the measured discharges for the test cases with high discharges. However, the average percentage error between measured and computed discharges has now reduced to 5.5 as given in Table 2, indicating a significant improvement of the results, as compared with the relationships that are based on a single non-dimensional parameter. The percentage error is not very much improved even if two parameters, $F r_{1}$, and $w / y_{1}$, are used to compute $C_{m}$ (see Table 2) and hence, the corresponding relationship is not given here due to it's poor correlation. 
Table 2 - Average percentage errors between measured and computed discharges using different equations.

\begin{tabular}{|c|c|c|}
\hline $\begin{array}{c}\text { Non-dimensional } \\
\text { parameters } \\
\text { used to express } C_{m}\end{array}$ & Eqn. & $\begin{array}{l}\text { Average \% } \\
\text { error using } \\
\text { Eq. (13) }\end{array}$ \\
\hline (i) $F r_{1}$ & (9) & 8.0 \\
\hline (ii) $w / y_{1}$ & (10) & 8.3 \\
\hline (iii) $(L / B)^{2}$ & (11) & 7.8 \\
\hline (iv) $F r_{1}, w / y_{1}$ & $\begin{array}{l}\text { (not } \\
\text { shown) }\end{array}$ & 7.9 \\
\hline $\begin{array}{l}\text { (v) } F r_{1}, w / y_{1},(L / B)^{2}, \\
\text { (Regression analysis) }\end{array}$ & (12) & 5.5 \\
\hline (vi) $\begin{array}{l}F r_{1}, w / y_{1},(L / B)^{2} \\
\text { (Numerical solution) }\end{array}$ & (14) & 5.7 \\
\hline
\end{tabular}

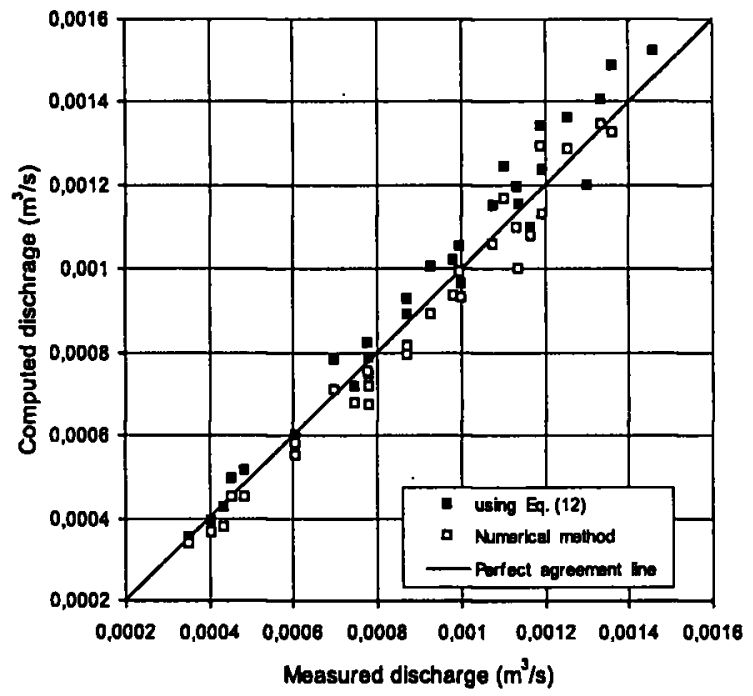

Figure 8 - Comparison between measured and computed discharges using Eq. (12) and numerical method.

\subsection{Numerical Solution}

The governing equation for discharge through a channel with side weir (Eq.(5)) was solved numerically using a fourth-order Runge - Kutta method treating this as an initial value problem. The main channel between sections (1) and (2) (see Figure 1) was divided into several sections having a spacing of $0.01 \mathrm{~m}$ between each section. The water depth and discharge at section (1) were used as the initial condition (Eq. (6)). After repeated computations, the water depths and discharges at other sections along the main channel were determined. Once the discharge at section (2) was computed, discharge over the side weir was estimated by taking the difference of discharges in the main channel between sections (1) and (2). In order to perform the above steps, the discharge coefficient should be known. For an assumed value of the discharge coefficient, the weir discharge was computed and then it was compared with the measured discharge to yield the average percentage error (E) as;

$E=\frac{100}{N} \sum_{i=1}^{N}\left|\frac{Q_{w c i}-Q_{w m i}}{Q_{w m i}}\right|$

where, Qwc and Qwm are computed and measured weir discharges, respectively, $N=$ number of test runs and $i=i^{\text {th }}$ test case.

By using trial and error procedure, discharge coefficients for each test case with minimum $\mathrm{E}$ were found. These discharge coefficients were finally related to non-dimensional parameters, $F r, w / y_{1}$, and $(L / B)^{2}$ to obtain the following linear relationship using multiple regression analysis.

$$
C_{m}=-0.511+0.93 F r_{1}-0.199\left(\frac{w}{y_{1}}\right)-0.137\left(\frac{L}{B}\right)^{2}
$$

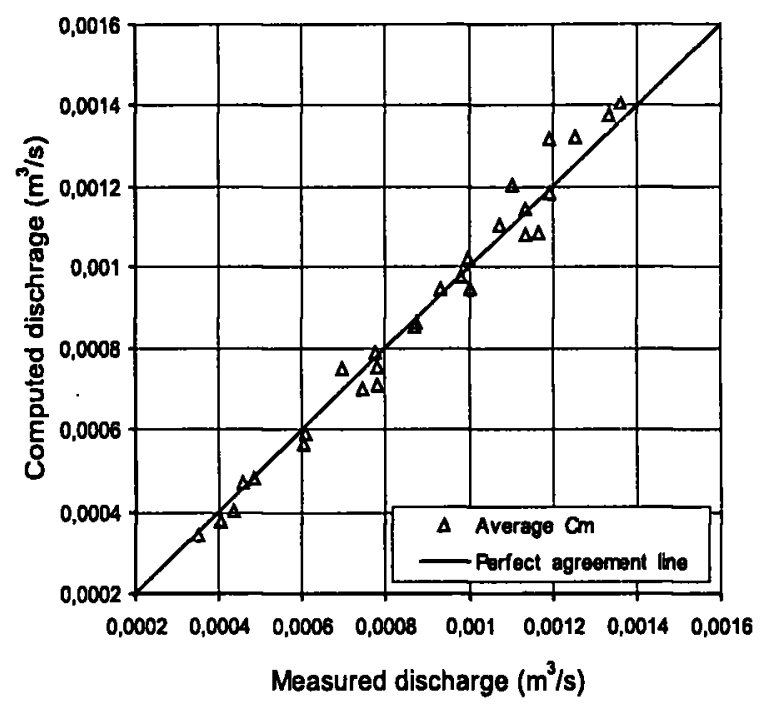

Figure 9 - Comparison between measured and computed discharges using average values of $C_{m}$.

The weir discharges computed using the discharge coefficients from Eq. (14) are compared with measured discharges in Figure 8. The average percentage error between measured and computed discharges is 5.7 which is comparable with the value obtained with the method used in sec.(4.1). The computed discharges are slightly lower than the measured discharges for most of the test cases and this may be attributed to the validity of assumptions made in deriving the governing equation. This was opposite in the previous analysis where 
most of the computed discharges are slightly higher than the measured. However, both functional relationships appear to give approximately similar results and hence, both are applicable for estimating the weir discharge in supercritical flows. If average values of $C_{m}$ are used from the Eqs. (12) and (14), the prediction of the weir discharge is further improved as shown in Figure 9, indicating the average percentage error of 4.2 .

\section{Summary and Conclusions}

A series of experiments was carried out to investigate the discharge over a rectangular, sharp-crested side weir with supercritical flow in the approach channel. The assumption of constancy of specific energy in the main channel along the side weir is valid within the range of supercritical flows generated in the experiments. The reduction of specific energy is about $3 \%$.

Using experimental data, a better correlation was established between the discharge coefficient and the non-dimensional parameters, $F r_{1}, w / y_{1}$ and $(L / B)^{2}$. It was noted that the discharge coefficient increases with the upstream Froude number in supercritical flows, whereas in subcritical flows, this behaviour was reported to be completely the opposite. Alternatively, the spatially varied flow equation in an approach channel with a side weir was solved numerically and another relationship was derived between the discharge coefficient and the same non-dimensional parameters. Both relationships proposed here are equally good when predicting discharge over side weirs with supercritical flows. It is important to note that the validity of the results presented here is limited to the range of upstream Froude numbers used in this study.

\section{Acknowledgments}

The paper was drafted during the first author's associateship visit to the Abdus Salam Int. Center for Theoretical Physics (ICTP), Trieste, Italy and hence, the assistance of the ICTP as well as the Swedish International Development Cooperation Agency (SIDA) who sponsored the associateship is gratefully acknowledged.

\section{References}

1. Borghei, S.M., Jalili, M.R. and Ghodsian, M., "Discharge Coefficient for Sharp Crested Side Weir in Subcritical Flow", J. Hydr. Engrg., ASCE, Vol. 125(10), pp.1051-1056, 1999.

2. Chow, V.T., "Open Channel Hydraulics", McGraw-Hill, New York, 1959, pp.340-341.

3. El Khashab, A., and Sumith, K.V.H., "Experimental Investigation of Flow over Side Weirs", J. Hydr. Engrg, ASCE, 102(9), pp.1255-1268, 1976.

4. Ghodsian,M., "Supercritical Flow over a Rectangular Side Weir", Can. J. Civ. Eng, 30, pp.596-600, 2003.

5. Hager, W.H, "Supercritical Flow in Circular-Shaped Side Weir", J. Hydr. Engrg, ASCE, 120(1), pp.1-12, 1994.

6. Hager, W.H., "Lateral Outflow over Side Weirs", J. Hydr. Engrg, ASCE, 113(4), pp.491504, 1987.

7. Henderson, F.M., "Open Channel Flow”, The MacMillan Company New York, 1966, pp.273-275.

8. Jalili, M.R. and Borghei, S.M., "Discussion on Discharge Coefficient of Rectangular Side Weir", by D. Manivannan and T. Satyanarayana, J. Irrig. and Drain. Engrg., ASCE, 122(2), p.132, 1996.

9. Muslu, Y., "Numerical Analysis for Lateral Weir Flow", J. Irrig. and Drain. Engrg., ASCE, 127(4), pp.246-253, 2001.

10. Oliveto, G., Biggiero, V. and Fiorentino, M., "Hydraulic Features of Supercritical Flow Along Prismatic Side Weirs", J. Hydr. Res., 39 (1), pp.73-82, 2001.

11. Rammurthy, A.S, and Carbellada, L., "Lateral Weir Flow Model", J. Irrig. and Drain. Engrg, ASCE, 106(1), pp.9-25, 1980.

12. Ramamurthy, A.S, and Subramanya, K., "Uniformly Discharging Lateral Weirs", J. Irrig. and Drain. Engrg, ASCE, 104(IR4), pp.399-411, 1978.

13. Ranga Raju, K.G., Prasad, B. and Gupta, S.K., "Side Weir in Rectangular Channel", J. 
Hydr. Engrg., ASCE, 105(5), pp.547-554, 1979.

14. Singh, R., Manivannan D., and Satyanarayana, $\mathrm{T}$., "Discharge Coefficient of Rectangular Side Weirs", J. Irrig. and Drain. Engrg., ASCE, 120(4), pp.814-819, 1994.

15. Subramanya, K., and Awasthy, S.C., "Spatially Varied Flow over Side-Weirs", ). Hydr: Engrg., ASCE, 98(1), pp.1-10, 1972.

16. Swamee, P.K., Pathak, S.K. and Ali, M.S., "Side Weir Analysis Using Elementary Discharge Coefficient", J. Irrig. and Drain. Engrg., ASCE, 120(1), pp.742-755, 1994.

17 Swamee, P.K., Pathak, S.K., Mohan, M., Agrawal, K.S. and Ali, M.S. "Subcritical Flow over Rectangular Side Weir", J. Irrig. and Drain. Engrg., ASCE, 120(1), pp.212-217, 1994. 